\title{
'Passing of the Torch'*
}

There are many reasons that could bring a Brazilian President to Sweden and might, reciprocally, lead Brazilians to return the noble hospitality of which we have been the subjects here today.

First of all comes to mind the friendship we have proved capable of nurturing and that, despite the distance and the cultural differences which separate us, has remained solid, firm, and creative. It is this friendship that has certainly inspired such fruitful economic and trading relations as we enjoy, and has made for an atmosphere of confidence which propitiates the investments that are the outward expression of Sweden's part in Brazil's progress. The convergence of our points of view on major international problems, and our faithful upholding of the principles of the United Nations Charter, are other factors that make our dialogue easy, smooth, and productive.

This ceremony of Passing of the Torch focuses on the issue of the environment, about which our two countries have long shown deep concern, striving in international fora to achieve suitable solutions.

\section{Geographical Features in Common}

It occurs to me that the geographical features of Brazil and Sweden have several things in common. Thus in Brazil, more than $50 \%$ of our territory is occupied by Amazonia in the north, where the tropical forest predominates, its apparently uniform mantle of rain-forest veiling mineral deposits of great economic importance. Another feature of the Amazon region is its low demographic density and its population's ability to adapt to ecological conditions that others might find inhospitable.

In Sweden, a very large part of the country's territory is occupied by the northern provinces whose climate could not be more disparate from that of Amazonia, but is just as severe. This region is sparsely populated too, and also harbours mineral riches that contribute to this country's economic might.

All such comparisons are, however, flawed, as they lack scientific precision, and are purely evocative or even poetic: in their territorial make-up, Sweden and Brazil have each a Great North which it is their duty to conserve by means of adequate use of their natural resources, and by providing the populations that live and work there with means of advancement.

\section{Conservation of Amazonia}

In Brazil, we are firmly engaged in rationally conserving Amazonia. Significant results have already been achieved, with deforestation drastically curtailed in the last few months. We have been searching for new forms of action, a notable exemple of which has been the creation of a Foundation, with governmental and private capital, which has reafforestation plans for about 200,000 square

\footnotetext{
*Substance of speech delivered by HE The President of the Federative Republic of Brazil at the Ceremony of the Passing of the Torch on World Environment Day, 5 June 1991, in Stockholm, Sweden. - Ed.
}

kilometres in our Amazonia. The commitment of our people to save Amazonia has no limits, and I can assure you that it will indeed be saved.

This ceremony [of Passing of the Torch] is fraught with special meaning, and its symbolic essence should inspire action. In a year's time, practically all the world's States, represented at their highest level, will be gathered in Brazil for the United Nations Conference on Environment and Development. Twenty years will by then have elapsed since they met for the United Nations Conference on the Human Environment - to map out, for the first time, the political paths that might lead to Mankind being reconciled with Nature.

\section{Landmarks in the Environmental Movement}

We are now here to link those two related events together and, by reflecting upon them, to prepare ourselves to achieve the best possible results. The desirable continuity between Stockholm '72 and Rio '92 should not discourage us from noting the fundamental difference between these two events.

In 1972, the peoples of the world realized that the planet had a limited capacity for absorbing the continuous aggression perpetrated by Man with increasing voracity in the two hundred years since the First Industrial Revolution. There was generalized outrage at the pollution of the air in large urban centres, and of the waters of navigable waterways, of drinking-water springs, and of coastal zones. This was the situation fairly widely on every continent, but it was more noticeable in highlyindustrialized centres.

In the twenty years that followed, scientific observation has provided us with knowledge of global processes that are dismantling the planet's natural equilibrium. In some scientific circles, of course, there had long been an awareness of these global phenomena; but only recently has this knowledge spread to all levels of society. Thus in 1991 we know that there is a process of global warming under way and, although we are far from achieving accurate forecasts and measurements, we can foresee severe and widespread consequences.

No less important is the continuous loss of species of flora and fauna, the vanishing of unfathomed possibilities that 'carry to their graves' the secret of untapped genetic potential.

Every system has its limits, and the Earth is no exception to the rule. Human beings, we know for a fact, die if they suffer extensive burns; but as far as our planet is concerned, we do not yet have means of verifying these limits.

We do know, however, that the prevailing model of development can offer the Earth the spectre of grave diseases inflicted by industrial pollution, and the poisoning of the atmosphere, or other problems due to the destruction of the forests - all of which threaten the vital habitat components of soil, air, and water.

We also know that, while many natural resources are finite, human greed over consumption and profit have no limits. We must balance them to save The Biosphere. The necessary path is that of a profound revision of the current hegemonic development models. 


\section{To Seek a Balanced World}

In the balanced world that we must seek, new ethical standards are required to signal the limits to unacceptable forms of greed, and to define new models of relations among states. We must also accept the inescapable fact that environmental problems of transcontinental consequence cannot be tackled and put to rights by a single country's nor even a single region's efforts.

Stockholm '72 was a historic milestone which led to the environment being understood as a universal matter, particulary where the immediately perceptible problems that afflict the populations of the world are concerned. Rio ' 92 must be a Conference at which, near the turn of the century and millennium, Mankind will adopt the guidelines for policies that are designed to prevent [the scramble for] economic progress from obliterating efforts to promote welfare.

New models of development will be needed to deal with the global processes that threaten to undermine the very foundations of human existence. When we talk of such new models, we would like to make it clear that they apply just as much to less-developed countries as to the most highly industrialized ones. Rio ' 92 must, nonetheless, aim beyond the agenda of global processes and concern itself, at least by implication, also with local outcomes.

\section{Some Alleviation Already}

Twenty years on from Stockholm, the effects of the latter's deliberations are clearly observable in the great metropolises of the developed world. Cities and regions with a major concentration of heavy industry, whose atmosphere was virtually unfit to breathe, can now display reasonable levels of air quality. Rivers and lakes bordering on urban areas are now purer and more teeming with fish than was even deemed possible some years ago.

In short, the quality of life as a measure of environmental protection - allied to advances in science and technology and to economic progress - has now reached much higher levels among rich nations. This has been made possible by the availability of specific financial resources and by the development and application of appropriate technologies.

\section{Disheartening Results in LDCs}

The results achieved with regard to this issue of the combating of pollution and the improvement of sanitary conditions in urban centres - an important item on what we could call the 'Stockholm agenda' - have been frankly disheartening in the less-developed world.

The process of urbanization has accelerated in poor countries. It would, however, be difficult to classify urbanization as a Third World disease; it is rather a characteristic trend of the contemporary world.

The degree of urbanization is similar in Sweden and Brazil. The difference is simply that, in my country, the absolute figures are about twenty times what they are in Sweden, and although these proportions are not exact, it is obvious that Brazilian urban concentrations are vastly greater than Swedish ones.

In the last decade, financial resources have become scarce, and access to appropriate technology has been reduced - so worsening the plight of urban areas in developing countries. Projections for the end of this century and the beginning of the next millennium are frankly daunting.

I therefore have no hesitation in saying that a significant part of the conclusions drawn at the 1972 Conference have generated initiatives, behaviour, and benefits, that so far have been largely restricted to rich countries. The 1992 Conference will thus be an opportunity for making advances universal.

\section{Problem of Megalopolises Now-Global}

The drama of the megalopolises in developing countries cannot be treated as a local problem, as it affects hundreds of millions of human beings. It is a global problem on many counts - including, to cite just two glaring examples, the outbreak of epidemics and the generation of migratory flows [of humans].

The preparatory discussions for the ' 92 Conference have not yet given the urban predicament the attention it demands. Perhaps the urgency of taking decisions to implement international cooperation in this field has not yet made itself felt in developed countries, whose sights are set on so-called global themes.

International cooperation will be decisive, however, if we want effectively to build a new world. We know that a healthy planet demands fundamental transformations, which go beyond specific decisions in ecological matters. What is needed, in reality, is a new ethic - a new pattern of relations between Men and States.

Science and technology cannot flourish in a political or ethical vacuum: the needs for universal progress and the requirements of justice should define their use. If they fulfil their political functions, they will bring men and nations closer together, for they are instruments for the construction of peace.

\section{Necessity of Peace}

If we do not build solid and lasting foundations for peace, there can be no prospect of a healthy planet. If new patterns of cooperation between countries, determined by the ideals of social justice, are not implemented, our work in ' 92 will not have a steady anchor.

I am not proposing Utopias - ecological issues force Man to think in a global manner. Peace, ethic strengthening, prosperity, and justice among nations, are the necessary fruits of cooperation and understanding, and shall be the greatest lesson of Rio ' 92 .

We are going through times that require radical and profound changes. The period to come will require courage and determination of statesmen. Never before was cooperation so blatantly needed as on this unique, historical opportunity.

Courage to change with wisdom and perspective for the future gives a sense of humanity to the efforts of Mankind. We must not fail to listen to the claims of the peoples of a threatened Earth. I strongly appeal to delegations to come to the Rio de Janeiro Conference - to finish the work which was to markedly furthered in Stockholm, and to lay the foundations of future accomplishments for a 21 st century of fulfilled hopes.

FERNANDO COLLOR President of the Federative Republic of Brazil Office of the President

Brasilia

Brazil. 